\title{
Julio Moncada
}

\section{Evocación de Jacobo Danke}

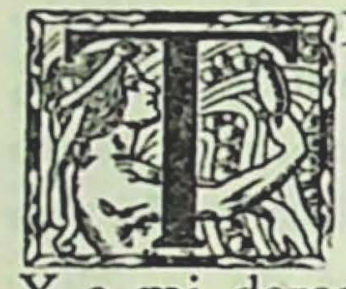

ENGO una biblioteca peregrina. Ha andado conmigo Y a mi derecha están ellos, los autores que me han dado tantas alegrías, de esas alegrías secretas, personales, íntimas. Esos autores que han ido dejando su formación en el alma de cada uno. Está, jcómo no estarlo! don Miguel de Cervantes. Es una obra de dos tomos, que este año enteró el centenario de su edición hecha en la calle de Santa Teresa número 8 en Madrid. Junto a él el viejo y querido Gorki. García Lorca y Miguel Hernández están trabados en el mismo escalón. Don Antonio Machado le da su mano venerable a la muy tremenda mano de Baudelaire. Junto a Rilke, el criollísimo Nicanor Parra, un poco más acá de adonde Manuel Magallanes Moure debe dialogar con su vecino, el epicúreo Omar Khayyam. No son muchos libros. Llegarán acaso a los dos centenares pero han sido un dulce sacrificio de llevar y traer, de casa a casa, de ciudad a ciudad, de país a país. Algunos amigos me han aliviado de vez en cuando de su peso, quedándose con el que más les interesó. $\mathrm{Y}$ más de algún vista de aduanas, ha sospechado de mí en virtud de tanto 
cajón con papel impreso, que superó siempre el volumen de las valijas, al equipaje personal del indómito viajero bibliómano.

Cuando siento que las esencias nacionales me están urgiendo a regresar hacia mis raíces, entonces me voy al rincón donde están mis amigos silenciosos. $\mathrm{Y}$ en las más altas horas de la noche, en el medio del gran silencio que sube desde el Río de la Plata, me pongo, mano a mano, a conversar con ellos como si vinieran llegando de visita desde mis valles lejanos. Es el país entero el que recorro, así, entre las líneas de tantos amigos.

Ayer me encontré con Jacobo Danke. Metí el dedo entre dos tomos gruesos y extraje un libro pequeño. Eran Las Barcarolas de Ulises. Dicho libro fue publicado el año 1934, hace la friolera de veintidós años, en Santiago de Chile, por la Editorial Ercilla. Está ilustrado por el viejo amigo del autor, Aníbal Alvial. Sus hojas empiezan a ponerse amarillas en los bordes. La impresión del lomo hecha en un verde claro, se ha transformado en amarillo por el sol que alguna vez le diera desde quién sabe qué ventana frontera.

Sentí un gran placer al verlo. Instantáneamente me acordé de otro libro de poesía de Jacobo, otro, que seguramente el autor no ama tanto como alguno posterior, pero que incuestionablemente, significa al poeta Jacobo Danke, tanto, como Todos fueron de este mundo significa al prosista Jacobo Danke. Me acordé de aquel libro que se llama Baladas del País de los Vientos hurtado de mis anaqueles en su oportunidad por algún impaciente poeta joven. $\mathrm{Y}$ me acordé de aquella pieza antológica de la poesía nacional que se titula: "Biografía de la Taza de Té”. Todo esto, mientras abría las páginas de Las Barcarolas, aquellas páginas tan libres, tan puras, tan sin literatura medida, pesada, sometida al regodeo estilístico.

Danke, se me apareció de pronto con todo su volumen dentro de la literatura chilena. No porque antes no le considerara y mucho, sino porque así, a la gran distancia física pareciera que aquello del espíritu es más posible de medir. Se me apareció Jacobo, con su estampa de navegante transmutado en escritor, en hombre que anda por las calles de la ciudad, que vive la vida de nuestros conciudada- 
nos, metido ocho horas en una oficina, tecleando en una máquina papeles que no son los papeles que debiera escribir durante ocho horas. Y creí necesario hacer constar este recuerdo en letras de molde para que se sepa, así, públicamente, que nuestros escritores no están arando en el mar con sus libros. Yo sé cómo de improviso al autor se le viene encima una sensación de soledad y de dudas sin cuento. Aunque tenga, como en el caso de Jacobo, diez o doce libros publicados, varios premios de esos que surgen por ahí, al acaso de los empellones sociales. Generalmente a nuestros autores se les glorifica después. Cuando se deposita el ataúd al borde del nicho, entonces sus amigos elevan la voz en la tarde del cementerio para cantar los elogios que el muerto se mereció durante toda la vida. Y, ¿ por qué no decirlos antes? Con el libro de Jacobo entre las manos, busqué otros. Y salió al camino La Estrella Roja, sobradamente conocida para hacer comentarios críticos de ella. Además, estas líneas no son un ensayo ni una estimativa de la literatura de Danke. Eso lo hacen y harán los críticos oficiales. Yo me he sentido siempre soldado. Y como tal admiro a este otro soldado que ha escrito tantas obras donde late un sentido humano profundo y se evidencia un poder artístico de consideración. Danke es un poeta de los más equilibrados estéticamente que ha dado Chile. Porque en él no sólo entregó la obra literaria sino además y como regalo especial todo un aporte humano a nuestra creación artística. Siempre le vi en hermano mayor de sus camaradas. A su dedicación a la amistad se debe, entre otros libros conseguidos y macizos, Los hombres oscuros, de Nicomedes Guzmán, que antes de la publicación de su primera novela, habíala escrito en quinientas páginas con otro título y muchos errores. Jacobo fue quien orientara al gran novelista joven chileno. Y con sus consejos, con su asiduidad compañera, Nicomedes Guzmán consiguió la obra que admirara la crítica chilena de la época.

Hubo algún año en que los tres, Danke, Nicomedes Guzmán y el que esto escribe, cenaban juntos todas las noches. Por allá por la segunda o la tercera cuadra de San Diego, o al costado del cerro Santa Lucía, en figones de filibusteros, obreros, carabineros y emplea- 
das de casas rumbosas. Comíamos pescado frito con ensaladas de cebolla y tomate. Y bebíamos vino tinto, espeso y caudaloso. Hablábamos de muchas cosas. Era la guerra mundial, la guerra donde, según nos decían, se jugaba el destino de la humanidad. $Y$ por la noche municipal de Santiago, cuando las barredoras edilicias lanzaban sus chorros de agua limpiando las aceras, caminábamos enyugados por una misma meta. Oímos muchas cosas que no se escriben después. Pero Jacobo escribió algunas. Por ejemplo, salió de aquellos meses de San Diego, La Taberna del Perro que Llora, auténticos relatos de esos días, centrados en los comedores donde imprecábamos nuestras miserias junto a las tristes mujeres que iban a cenar antes del "trabajo" a que las condenaba la sociedad cristiana. En aquel bar, extenso y mal alumbrado, donde alguna vez le dí la mano a un célebre delincuente, o donde alguna otra mataran a otro descarriado criminal, efectivamente había un perro que llegaba todas las noches. De gran alzada, amarillo, híbrido de todo hibridismo, con el rabo cortado a dentelladas, se sentaba junto a la puerta que daba al pasillo, moviendo nerviosamente las orejas. Ya los parroquianos le conocían. Y alguno desde su mesa, mostrándole un trozo de pan le llamaba. Acudía el perro, meneando el rabo. $Y$ cuando ya cerca del codiciado mendrugo, apuntaba la avidez en las fauces entreabiertas, el juguetón comensal le retiraba el manjar. Entonces el perro aullaba. Cortaba de pronto el ruido de los cubiertos rasguñando los platos el aullido del perro, que, uno tras otro, lanzaba sus lloros sobre el pan que se alejaba. La escena se repetía una y otra vez. Nosotros, jamás lo hicimos. Nos daba dolor ver esa necesidad frustrada, esa angustia perruna sometida al capricho humano. Pero ese perro, esas mujeres, esos hombres todavía humedecidos por el sudor de las fábricas, fueron los materiales próximos que tomara el novelista para sus relatos del libro a que aludo.

Después, han seguido los libros. Libros del mar casi todos, libros donde una angustia humana anda por ahí metida en todos los recovecos de sus páginas mostrando en la interpretación artística un vigor 
clásico, un aliento épico del triste hombre de nuestros días, sometido, esclavizado, paupérrimo.

Jacobo no es hombre de corrillos literarios ni de organizaciones de autobombo. Pertenece y perteneció siempre al hogar. Cuando no lo tuvo anduvo buscándolo para refugiarse en la intimidad y sentir el dulce coloquio del amor. Jamás ha administrado -como tantos otros- su producción literaria. $\mathrm{Ni}$ se ha prodigado en prólogos ni conferencias, ni ha proclamado nuevas formas estéticas. Cumple quizá si con excesiva parquedad su destino limpio de escritor. Cada tanto tiempo, aparece en las librerías un título de sus libros. Pero no constituye un libro más. En el fondo de las provincias chilenas, donde la lluvia cae con desesperación o el sol resquebraja las costras salitrosas, los jóvenes y las jóvenes leen sus páginas donde aprenden ese alfabeto innominado de la vida real, sin afeites, vida regada en todas sus formas plurales a través de personajes auténticamente vivos. Podríamos, si quisiéramos, enjuiciarle estéticamente, decir que pertenece a tal tendencia, que su estilo es identificable en tal modulación, etc. Pero no es esto lo que importa. Al menos para mí, en esta noche de Montevideo, cuando miro tres de sus libros sobre la mesa de los trabajos y al abrir al azar uno de ellos me encuentro con el Océano Pacífico, bramando y resoplando bajo las hojas quietas: " $\mathrm{Ca}$ llad conmigo los desesperados. - Piedad bermeja de panales, brizna - de rubias hebras era el mar que urde - baladas de oro frente a Curaumilla. - Callad conmigo. Era un país de aria, un humo blanco de odas y marimbas... - Callad. Un rastro de leyenda, estuario - de miel... iy en él mi juventud perdida!"

No. No perdió su juventud Jacobo Danke. Su hermosa juventud abierta para cien ideas, dispuesta a entregarse en batallas sin término, atada a veces en escritorios burocráticos, dispersa otras por el mar mexicano en la bruja noche de Veracruz. Su juventud está perpetuada allí, en todas partes donde haya un hombre que llora por un mendrugo. $\mathrm{Y}$ donde haya un escritor que lo diga.

Nuestra triste mezquindad nacional no siempre ha dicho de Danke. lo que su obra merece. No aspiro a que estas líneas sean 
una glorificación de sus merecimientos. Hay otros más autorizados para hacerlo. Estas palabras son sólo un recuerdo, una evocación, no sólo de sus libros si no de él mismo. Se evaden de lo estrictamente literario para entrar a lo personal. Pero el hombre es indivisible de su obra y en este caso de Jacobo Danke, se justifica una vez más esta armonización. Bellos libros y bella vida para ejemplo de literatos y de hombres. Acaso me quede muy por debajo de lo que pudiera decir. Es sólo una evocación. Una visión nocturna que llegó desde muy lejos, desde muchos años, desde muchas cosas. Como el ruido de la lluvia en las ventanas. 